\section{JOHN WESLEY AND EVOLUTION}

To the Editor of ScIence: In a recent book on "Evolution and Animal Life" the authors, Jordan and Kellogg, attribute the following to John Wesley:

The ape is this rough draft of man. Mankind have their gradations as well as other productions of our globe. There is a prodigious number of continued links between the most perfect man and the ape (p. 452).

As a matter of fact, these statements, selected from different connections, are not attributable to Wesley in any proper sense. That they were thus ascribed to him by the authors probably grows out of the circumstance that in a work by this author, entitled "A Survey of the Wisdom of God as Revealed in the Creation, or A Compendium of Natural Philosophy," is contained extended quotations from Bonnet's " Contemplation de la Nature," and that among these may be found the passages in question, erroneously ascribed to $\mathrm{Mr}$. Wesley. That the latter author gave the views concerned some measure of approval may be inferred in that he introduces the quotations in the following cordial terms:

This reflection upon the scale of beings, is pursued at large by one of the finest writers of the age, Mr. Bonnet, of Geneva, in that beautiful work, "The Contemplation of Nature." When I first read this, I designed to only make some extracts from it, to be inserted under their proper heads. But under further consideration, I judged it would be more agreeable, as well as more profitable to the reader, to give an abridgment of the whole, that the admirable chain of reasoning may be preserved, etc. ${ }^{1}$

However, not only in this indirect way may the interest of this versatile and scholarly theologian be inferred. The body of the work abounds in illustrations of intelligent sympathy with scientific activity and progress. And the authors of "Animal Life and Evolution" might have cited passages, almost as pertinent as those above, directly from $\mathrm{Mr}$. Wesley. For example, on p. 148, Vol. I., may be read the following:

${ }^{1}$ Cf. supra, 3d American edition, Vol. II., p. 185; and for the passages in question, ibid., pp. $208,211$.
Animals of the monkey class are furnished with hands instead of paws; their ears, eyes, eyelids, lips and breasts are like those of mankind; their internal conformation also bears some distant likeness; and the whole offers a picture that may mortify the pride of such as make their persons the principal objects of their admiration. These approaches are gradual, however,. and some bear the marks of our form more strongly than others. In the ape-kind, we see the whole external machine strongly impressed with the human likeness; these walk upright, want a tail, have fleshy posteriors, have calves to their legs, and feet nearly like ours. In the baboon-kind, we perceive a more distant approach; ... the monkey-kind are removed a step further, etc.

\section{Chas. W. Hargitt}

\section{TWO FLEA REMEDIES TO BE TESTED}

Aside from great annoyance caused by fleas, their agency in the carriage of the bubonic plague has been so well established that it is important to test every proposed remedy or preventive. Since the publication of my circular No. 13 on this subject, I have received information concerning two remedies vouched for by careful persons, but have not had a good opportunity to test either. I hope that readers of ScIEnce having the opportunity will try these remedies and will let me know the results.

Mr. E. M. Ehrhorn, the well-known entomologist who is deputy commissioner of horticulture in California, gives me the following: Fill a soup-plate with soapsuds; in the center place a glass of water with a scum of kerosene on top; place the soup-plate on the floor in an infested room, and set fire to the kèrosene at night. Fleas in the room will be attracted and will jump into the soapsuds.

Another remedy is sent me by the wellknown writer on ants, Miss Adele M. Fielde, with the request that I make it widely known. Miss Fielde states that during long residence in southern China, where fleas swarm even in clean houses, she made her own house immune through many years, by dissolving alum in the whitewash or kalsomine that covered the interior walls, putting sheets of thick paper that had been dipped in a solution of alum under the floor matting and scattering pul- 